\title{
Adhesive material property evaluation for improved Lamb wave simulation
}

\author{
W.H. Ong ${ }^{a^{*}}$, N. Rajic ${ }^{b}$, W.K. Chiu ${ }^{a}$, C. Rosalie ${ }^{b}$ \\ ${ }^{a}$ Department of mechanical and aerospace engineering, Monash University, Wellington Rd, Clayton, VIC 3800, \\ Australia \\ ${ }^{\mathrm{b}}$ Defence Science \& Technology Group (DSTO), 506 Lorimer St, Fishermans Bend, VIC 3207, Australia \\ * Corresponding author: wern.ong@monash.edu
}

\begin{abstract}
Lamb waves are commonly modelled in isotropic metals such as steel and aluminium which have well-known published properties. When attempting to model Lamb waves in polymer materials with viscoelastic properties such as epoxy adhesives, it is not sufficient to rely on published properties which are usually based on quasistatic mechanical testing. This is due to Lamb waves creating an elastic disturbance with a relatively low strain amplitude but high strain rate. Unlike in metals, the modulus of a viscoelastic material is dependent on strain rate. Therefore to accurately model the behaviour of Lamb waves in polymers, the properties of the host structure must be obtained using methods that reproduce the strain amplitudes and strain rates of the intended application. This paper presents an investigation of three ultrasonic methods for determining the material properties of a film adhesive. It is found that the elastic modulus required to accurately model Lamb waves in this adhesive is approximately $60 \%$ higher than the value determined by conventional quasi-static testing. Finally, a Lamb wave simulation is used to illustrate that such discrepancies can lead to significant differences in the scattered wave field from a bond-line defect.
\end{abstract}

\section{Keywords}

FM300, film adhesive, material property, Lamb wave, numerical simulation

\section{Introduction}

Lamb wave based structural health monitoring (SHM) technologies have the potential to radically improve the efficiency and effectiveness of inspections of structural fatigue [1] and other forms of structural damage in 
engineering assets. Lamb waves can propagate across plate structures, allowing them to inspect large areas. Lamb waves can propagate in two distinct modes (symmetric and antisymmetric) relative to the thickness plane of the plate. There are an infinite set of each mode type that can exist in a plate. Some of the modes can be sensitive to structural inhomogeneities and give rise to scattering and mode conversion. An understanding of these interactions for a given structural application can be obtained either empirically, analytically or by numerical modelling with the latter generally the most versatile and powerful. Typical implementations include finite element analysis (FEA) [2, 3], local interaction simulation approach (LISA) [4, 5] and spectral element method (SEM) [6]. The literature contains numerous examples of the successful application of FEA to model Lamb waves for structural inspection $[3,7-10]$ in metallic structures. One of the fundamental requirements for an accurate predictive model is a precise set of elastic properties. Typically, elastic properties reported by manufacturers are determined from static testing. This has been shown to be sufficient when modelling the propagation of Lamb waves in metallic structures by Ong et al [11] and also Ambrozinski et al [12]. During the study dispersion curves generated using static material properties could be matched to experimentally measured dispersion characteristics. Similarly, Ambrozinski et al [12] showed that ultrasonically obtained Young's modulus for aluminium was within $1 \%$ of that obtained using a quasi-static 3 point bending test.

In contrast, relying on statically determined elastic properties for viscoelastic materials such as adhesives can lead to significant error due to strain rate sensitivity. Rocheford and Brinson [13] conducted stress-strain measurements on FM-300 over a time period of 1, 10 and 30 minutes with each returning a different elastic modulus. The fastest measurement (1 minute) returned the highest modulus. Similarly, Gilat et al [14] found PR-520 epoxy had a Young's modulus of $3.54 \mathrm{GPa}$ at $1.76 \mathrm{~min}^{-1}$ strain rate and $7.18 \mathrm{GPa}$ at $420 \mathrm{~min}^{-1} \mathrm{strain}^{-1}$ rate. Therefore it is expected that modelling of high strain rates occurring during Lamb wave propagation in film adhesives, will require a higher modulus [13-17] when compared to static structural modelling. For this reason, Maheri and Adams [18] resorted to empirical relationships to model adhesives under dynamic loading. Therefore, the properties must be determined under experimental conditions that are appropriate to the propagating Lamb wave in the adhesive layer. This potential difference in properties is highlighted by Ong et al [11] where published properties originating from static testing were used to predict the dispersion curves for a composite plate. When the prediction was overlaid on measured dispersion curves, a $25 \%$ error in wavenumber was observable. While a composite plate differs from a film adhesive, the work is still relevant as the epoxy matrix in a composite also has viscoelastic properties. 
Using statically derived properties when performing numerical studies can have widespread consequences on the predictive capability since bonded joints which employ film adhesives are commonly used in many aircraft structures. As noted by Lowe et al [19], the transmission of Lamb wave across adhesively bonded joints has important industrial relevance. A good understanding of the science behind this phenomenon is crucial for the development of techniques for the inspection of adhesively bonded metal and composite joints. Work reported by Francesco and Rizzo [20] showed that the transmission coefficient of Lamb waves propagating across bonded lap-shear joints is affected by the elastic properties of the adhesive forming the joint. In their study, it was shown that the transmission coefficient across the bond was highly sensitive to whether the bond was fully or poorly cured which is closely related to the adhesive modulus.

In order to obtain the appropriate properties for modelling Lamb wave propagation in bonded joints, it is proposed that the material properties should be determined under ultrasonic excitation. Several methods have been published for this task. Spencer et al [21] presented a time domain method which was used to fit the waveform from a model to an experimental target waveform by optimisation of the model's material properties. Similarly, Ambroszinski et al [12] and Ong et al [22] have presented frequency domain methods which iteratively optimise material properties in a model until the output dispersion curves match their experimental target. The present paper follows in the footsteps of these publications and examines three ultrasonics based methodologies for estimating the stiffness of structural epoxy adhesive. The main subject of the investigation is FM300-2K, a high performance epoxy film adhesive commonly used for secondary bonding applications in aerospace, although the methodologies proposed in this paper are applicable more generally.

The first method of determining the elastic properties of the adhesive relies on the propagation of bulk waves in a monolithic block of adhesive (i.e. in its bulk form). This is based on the work by Burst and Adams [23] who reported that the material properties of structural adhesives obtained in bulk form are valid for use in structural analysis of in-situ thin-film adhesives. The second method involves the use of a plate made from a sheet of adhesive. In both methods, the adhesive is unconstrained in the sense that it is not adhered to a substrate like in a bonded joint, nor is it consistent in thickness to a typical bond line. To assess whether such details are significant factors in the determination of elastic properties for Lamb wave modelling, a third method was developed. In this method the elastic properties of the film adhesive are derived indirectly from a Lamb wave transmission spectrum measured on an aluminium sample with a thin layer of epoxy. Prior to investigating these methods, the elastic properties of the subject material (FM300-2K) were determined using a standard quasi- 
static method. This was done with two main purposes in mind: (i) to establish a baseline, and (ii) to validate the elastic properties listed by the manufacturer, which in turn would provide assurance in the manufacturing process.

\section{Property evaluation methods}

Three different types of specimens: a monolithic block, a thin monolithic sheet and a metallic plate with a surface bonded strip of epoxy, were manufactured. All three were produced in an autoclave using a consistent cure cycle that conformed to the manufacturer's recommendations. However, the precise details of manufacture varied slightly between the specimen types; those details are discussed in the relevant subsections.

\subsection{Quasi-static testing method}

In this method, three narrow strips were cut from a thin monolithic sheet of epoxy using a milling machine. Each strip was fitted with a strain gauge and subjected to a tensile test using a mechanical testing machine as shown in Figure 1. The tensile machine was set to stretch the specimen at a rate of $0.5 \mathrm{~mm} / \mathrm{min}$ ensuring a low strain rate of $0.142 \mathrm{~min}^{-1}$. The force applied was logged using a $1 \mathrm{kN}$ load cell and the cross sectional area was measured using digital callipers to evaluate the stress in the specimen. Figure 2 shows the result from the stressstrain data logging for the three strips. From this data, the Young's modulus was calculated by taking the slope of the stress-strain curve between 500 and $2000 \mu$ strain. This range is used because it is within the linear elastic region of the material and is considered standard practice for traditional tensile testing. The results are summarised in Table 1 where the average Young's modulus is $2.90 \mathrm{GPa}$. These values are close to those published by the manufacturer [24] and nearly identical to that measured by Tong et al [25]. 


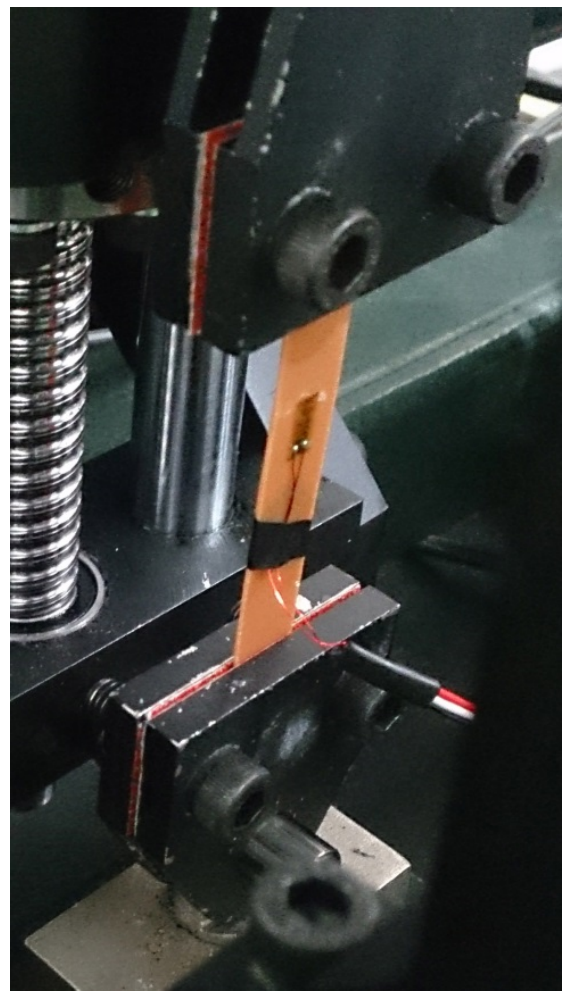

Figure 1 FM300-2K specimen with strain gauge attached in tensile machine.

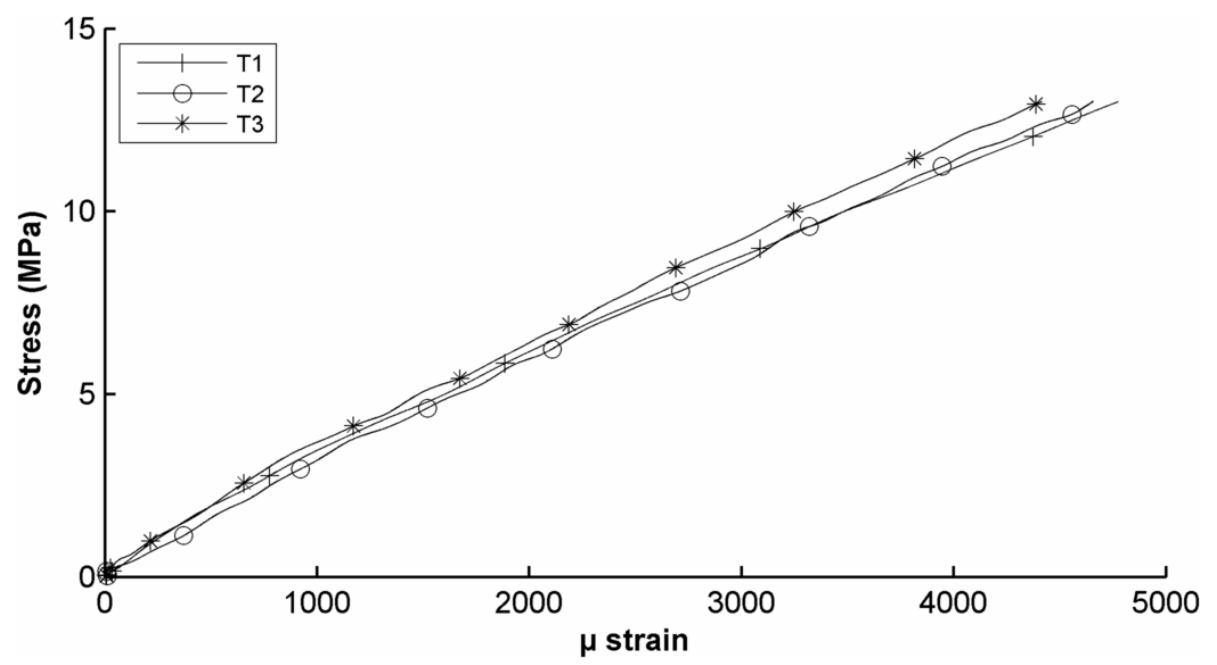

Figure 2 Stress-strain curves from tensile testing FM300-2K specimens.

Table 1 Modulus obtained from tensile specimens and published properties. Note: * Cytec only provide shear modulus, Young's modulus was calculated using Poisson's ratio from Tong et al [25]

\begin{tabular}{l|c|c|c|c|c|c} 
Specimen & $\mathrm{T} 1$ & $\mathrm{~T} 2$ & $\mathrm{~T} 3$ & Average & Cytec & $\begin{array}{c}\text { Tong et } \\
\text { al }\end{array}$ \\
\hline Young's modulus (GPa) & 2.82 & 2.91 & 2.97 & 2.90 & $2.432^{*}$ & 2.923
\end{tabular}




\subsection{Bulk wave propagation in a monolithic block}

The elastic properties of the structural adhesive FM300-2K were calculated based on the speed of bulk waves propagating across a thick specimen. The specimen was constructed using enough layers of film adhesive to build a total thickness to $22 \mathrm{~mm}$, which was deemed sufficient for an accurate measurement of the bulk wave speed. The final specimen dimensions were $40 \mathrm{~mm}$ x $40 \mathrm{~mm}$ x $22 \mathrm{~mm}$. The property determination technique is detailed in a document published by Olympus [26] where it is stated that Poisson's ratio and Young's modulus can be calculated by the following equations:

$$
\begin{array}{lr}
v=1-2(V T / V L) 22-2(V T / V L) 2 & \text { Equation } 1 \\
E=V L 2 \rho(1+v)(1-2 v)(1-v) & \text { Equation } 2
\end{array}
$$

\begin{tabular}{|c|c|c|c|c|}
\hline$v=$ Poisson's Ratio & $\begin{array}{l}V L=\text { Longitudinal } \\
\text { Velocity }\end{array}$ & $V T=$ Shear Velocity & $\rho=$ Density & $E=$ Young's \\
\hline
\end{tabular}

Where

Normal incidence shear wave measurements were taken with a Panametrics V155 transducer, while longitudinal waves were measured using a Panametrics A106S transducer. Both transducers were driven by an Olympus EPOCH XT ultrasonic flaw detector. The EPOCH XT was set to excite the transducers with a $5 \mathrm{MHz}$ pulse excitation. Bulk waves are typically accepted as having constant wave speeds with regards to frequency so the choice of excitation frequency can be arbitrarily set for this experiment.

Figure 3 shows the experimental setup where the FM300-2K specimen has an A106S transducer placed on the top face. The setup is a conventional pulse-echo arrangement. In this mode, the EPOCH XT presents the wave data in the form of an A-scan which also has automated gating to determine the time of flight (TOF) of waves reflecting from the specimen's opposing face.

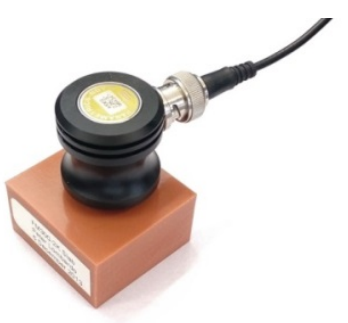

Figure 3 FM 300-2K slab specimen with actuator. 
Table 2 summarises the data captured from the bulk wave method and presents the calculated modulus and Poisson's ratio from the measured longitudinal and shear wave speeds. It is noted that the elastic modulus is significantly higher than the values published by Cytec [24] (See Table 1).

Table 2 Results from bulk wave ultrasonic testing.

\begin{tabular}{c|l|c|l|c|c|c}
$\begin{array}{l}\text { Thickness } \\
(\mathrm{mm})\end{array}$ & $\begin{array}{l}\text { Longitudinal } \\
\text { wave } \\
\text { TOF }(\mu \mathrm{s})\end{array}$ & $\begin{array}{l}\text { Shear wave } \\
\text { TOF }(\mu \mathrm{s})\end{array}$ & $\begin{array}{l}\text { Longitudinal } \\
\text { wave speed } \\
(\mathrm{m} / \mathrm{s})\end{array}$ & $\begin{array}{l}\text { Shear wave } \\
\text { speed }(\mathrm{m} / \mathrm{s})\end{array}$ & $\begin{array}{l}\text { Poisson's } \\
\text { ratio }\end{array}$ & $\begin{array}{l}\text { Young's } \\
\text { modulus } \\
(\mathrm{GPa})\end{array}$ \\
\hline 21.94 & 19.65 & 43.1 & 2233.1 & 1018.1 & 0.37 & 3.74
\end{tabular}

\subsection{Dispersion curve fitting method}

The dispersion curve fitting method uses the dispersive characteristics of propagating Lamb waves across a plate specimen. The plate specimen is shown in Figure 4 which consists of FM300-2K film adhesive cured to a thin plate of thickness $0.69 \mathrm{~mm}$. After curing, the plate was trimmed to a planar dimension of $300 \mathrm{~mm} \times 300 \mathrm{~mm}$. A $\varnothing 10 \mathrm{~mm} \times 1 \mathrm{~mm}$ thick Ferroperm piezoceramic disc of type Pz27 was placed at the centre of the plate in order to excite Lamb waves. The acoustic response of the panel was measured along Line 1 (Figure 4) using laser vibrometry (LV) as shown in Figure 5 and described in $[3,8]$. The piezoceramic disc was driven using Hanning windowed sinusoids with centre frequencies ranging from $100 \mathrm{kHz}$ to $500 \mathrm{kHz}$ at $50 \mathrm{kHz}$ intervals.

The time-displacement data acquired along line 1 was transformed using a two dimensional fast Fourier transform (2D FFT) [27] into the frequency-wavenumber domain to separate the wave field into its constituent modes. The result from the 2D FFT is shown in Figure 6 in the form of an intensity plot which is superimposed on predictions furnished by the commercial DISPERSE package [28]. The properties used to predict the modes via DISPERSE's global matrix method (GMM) solver are listed in Table 3. The Young's modulus was obtained from Cytec's datasheet [24], while the density was not supplied and had to be determined by measuring the weight and volume of two samples cut from the plate as shown in Figure 7a. The thickness was measured along line 1 with a dial indicator mounted on a precision surface block as shown by Figure 7b.

When comparing the predicted values from DISPERSE against LV derived values for the fundamental modes shown in Figure 6, the wavenumber is over predicted for the $\mathrm{S}_{0}$ and $\mathrm{A}_{0}$ modes, by $27 \%$ and $18 \%$, respectively, at the mid-range frequency. 


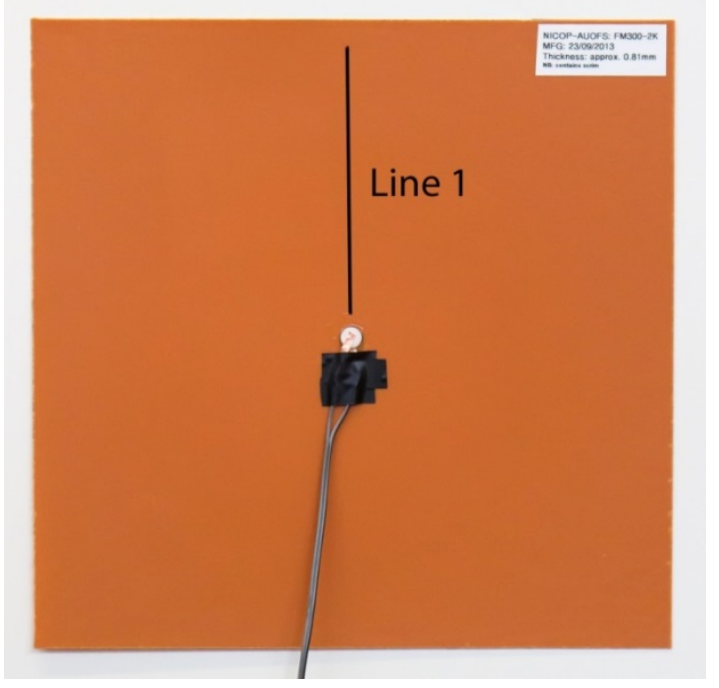

Figure 4 FM 300-2K specimen $0.69 \mathrm{~mm}$ thick with vibrometer scan line marked.

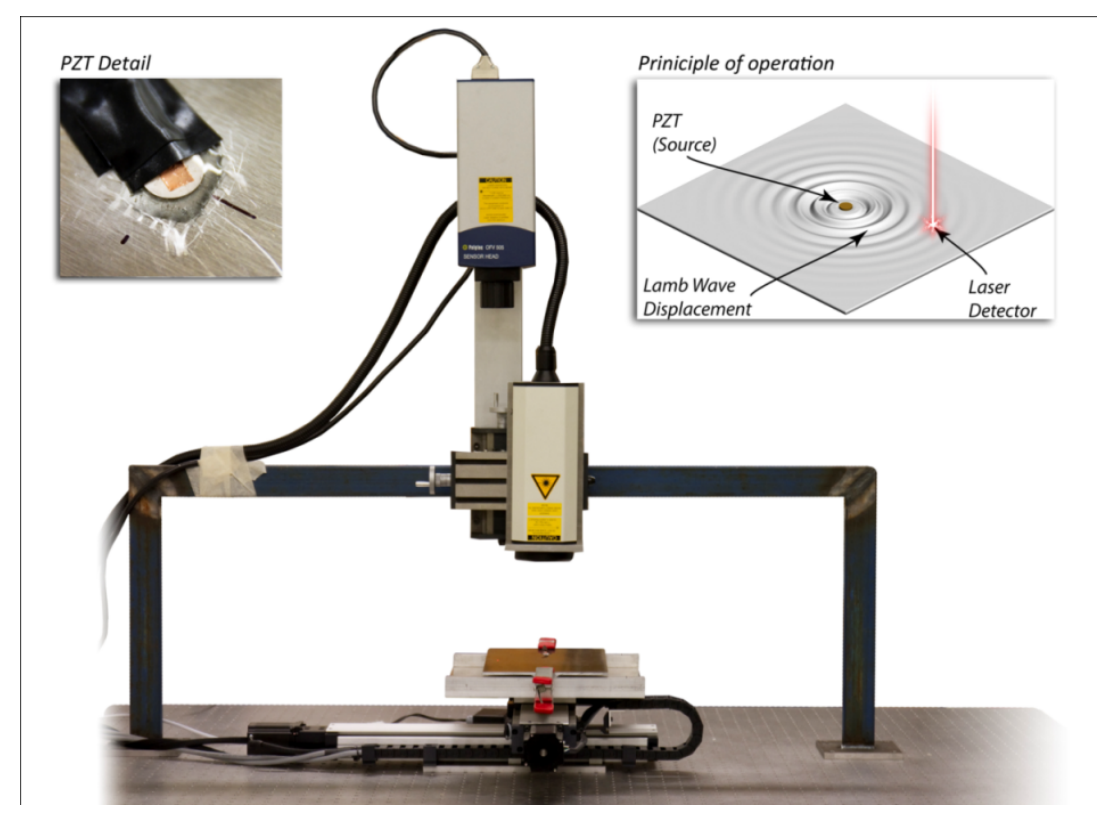

Figure 5 Laser vibrometry test set up

Table 3 Combined FM300-2K published and measured material properties.

\begin{tabular}{l|l} 
Young's modulus [24] (GPa) & 2.432 \\
\hline Density (measured) (kg/m $\left.\mathbf{m}^{\mathbf{3}}\right)$ & 1317 \\
\hline Poisson's ratio [25] & 0.34
\end{tabular}




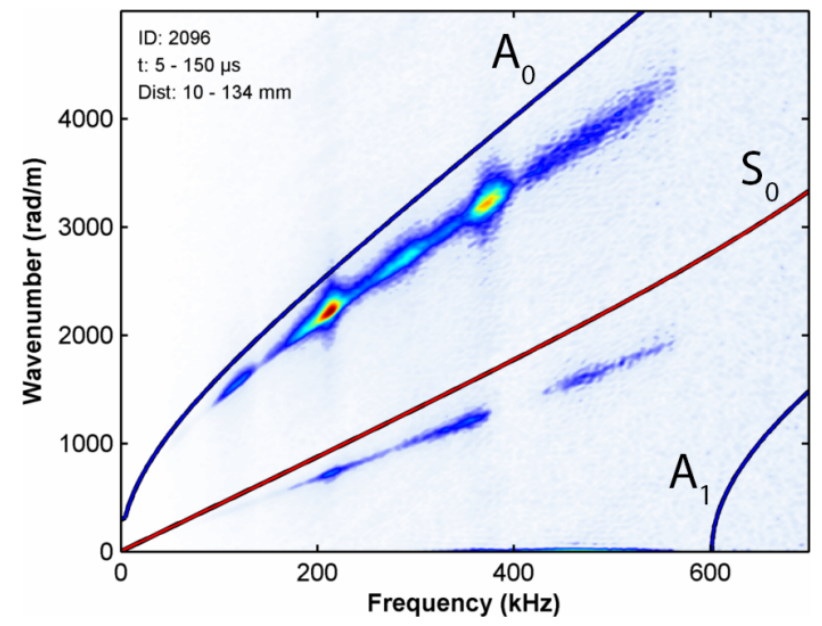

Figure 6 2D FFT showing Lamb modes with DISPERSE overlay (solid lines) calculated using published properties.

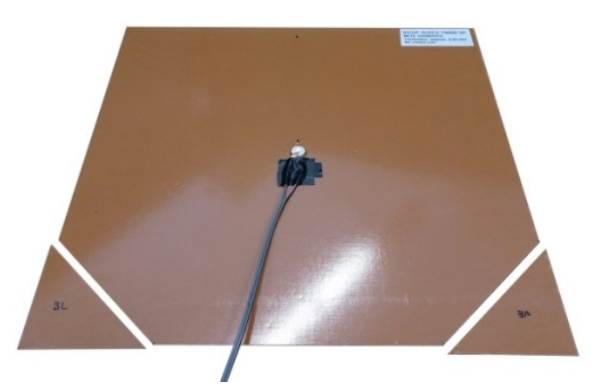

a)

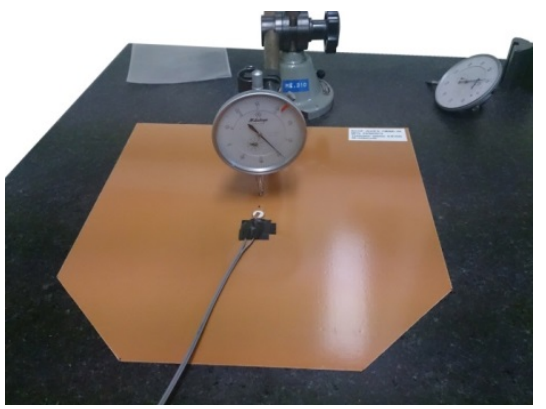

b)

Figure 7 a) Specimens cut for density measurement. b) Thickness measurement at plate centre with dial indicator.

An optimisation of the Young's modulus was performed through trial and error to improve the match between the DISPERSE prediction and the experimentally derived data. The problem was treated as a univariate optimisation problem with a well-bounded solution. The solution which achieved an excellent fit, shown in Figure 8a, resulted from using a Young's modulus of $3.9 \mathrm{GPa}$ which is $60 \%$ higher than the modulus published by Cytec [24], and marginally higher than the value determined by the previous bulk wave measurement. It is noted that the frequency dependence of the elastic modulus is not significant at this frequency bandwidth (that is, $100 \mathrm{kHz}$ to $500 \mathrm{kHz}$ ). After the optimisation of the Young's modulus, the Poisson's ratio was increased to 0.4 in DISPERSE to investigate its effect on the dispersion curves. The results, shown in Figure 8 , indicate that the dispersion curves are largely insensitive to Poisson's ratio within the range of 0.34 to 0.4 . When comparing the two extremes of the range $(0.34 \& 0.4)$ the net effect of increasing Poisson's ratio is a reduction in the $\mathrm{S}_{0}$ mode wavenumber dispersion curve thus leading to a barely perceptible improvement. This shows that the dispersion characteristics are more sensitive to the Young's modulus in this instance. 


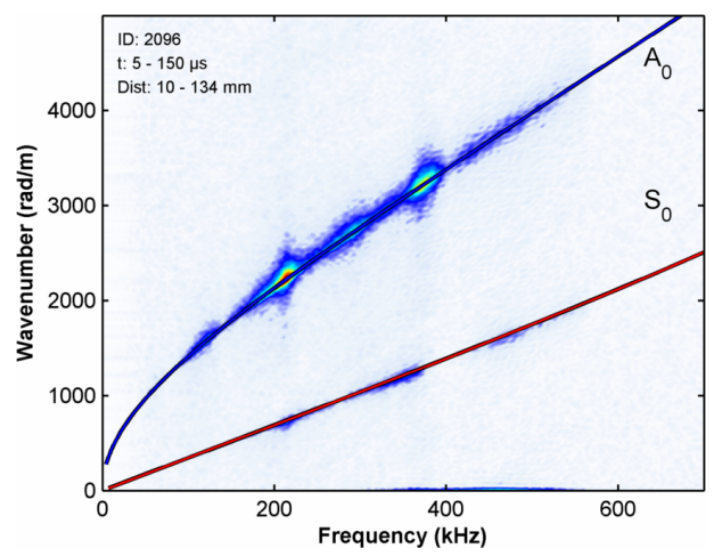

a) $v=0.34$

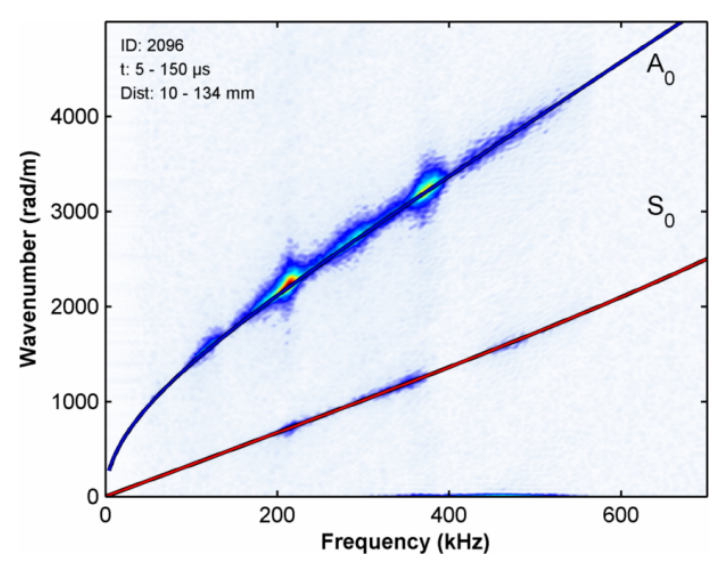

b) $v=0.40$

Figure 8 2D FFT overlaid with dispersion curves (solid lines) from optimised properties.

\subsection{Attenuation spectrum method}

In both techniques previously presented, the adhesives were free monolithic specimens. In this section a new technique is described that enables a determination of the elastic properties of the adhesive when in a geometric form that more closely resembles a bond line. Given that the elastic properties of aluminium are well known [29], the properties of the film adhesive can be determined from the transmission spectrum of Lamb waves through a small section of adhesive bonded to one side of an aluminium test plate.

Figure 9 shows the setup used for this method. The specimen consisted of a $1.6 \mathrm{~mm}$ thick aluminium plate with a FM300-2K adhesive patch in the centre. The planar dimensions of the plate and the adhesive patch were 500 $\mathrm{mm} \times 500 \mathrm{~mm}$ and $200 \mathrm{~mm} \times 50 \mathrm{~mm}$ respectively. A piezoceramic disc, similar in dimension to that used on the monolithic adhesive plate, was positioned such that waves upstream and downstream of the adhesive could be monitored using LV. The drive signals were Hanning windowed sinusoids with centre frequencies ranging from $100 \mathrm{kHz}$ to $1 \mathrm{MHz}$ at $50 \mathrm{kHz}$ intervals. LV was used to record the time-displacement history of Lamb waves along the upstream and downstream lines (see Figure 9).

In this experiment, both $\mathrm{A}_{0}$ and $\mathrm{S}_{0}$ modes were excited simultaneously. In order to measure the amplitudes of the modes separately, the time-displacement history was processed using a 2D FFT. The upstream and downstream amplitudes of $\mathrm{A}_{0}$ and $\mathrm{S}_{0}$ modes were determined from the 2D FFT over the desired frequency range. Once the amplitudes had been determined, the attenuation spectrum was calculated using Equation 1. 
Where $\mathrm{f}$ represents the frequency under examination.

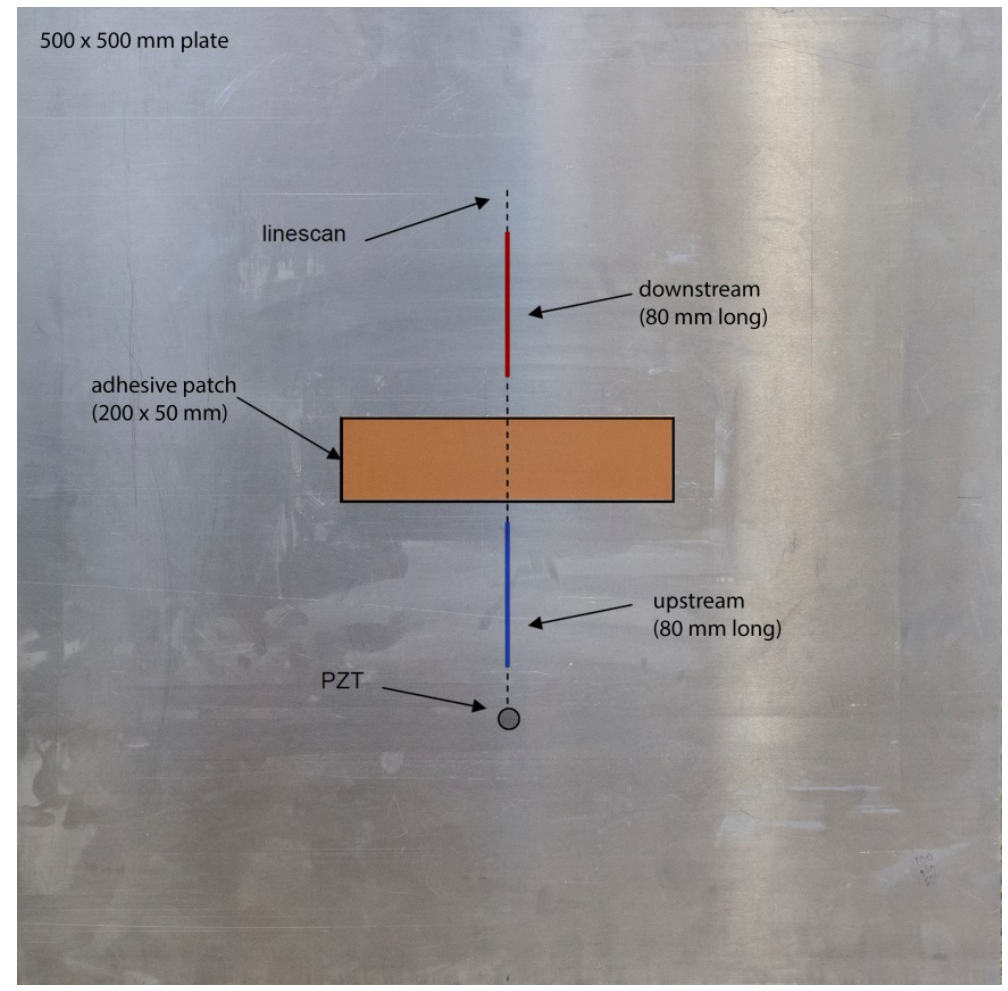

Figure 9 Aluminium-FM300-2K specimen with scan lines marked.

A 2D axisymmetric plane-strain numerical model of the aluminium plate shown in Figure 9 was created using COMSOL 3.5. The plate's cross-section was modelled along the "line scan" marked on Figure 9. 2D analysis was used because it would require substantially more time to model and solve the entire plate in $3 \mathrm{D}$. In order to excite Lamb waves in the model a time varying force was applied to one end of the $2 \mathrm{D}$ model representing the PZT. The time varying force consists of a superposition of several Hanning windowed sinusoids with centre frequencies ranging from $100 \mathrm{kHz}$ to $1 \mathrm{MHz}$ at $50 \mathrm{kHz}$ intervals. A transient dynamic time marching solver was used to simulate the Lamb waves and obtain the out of plane displacement as indicated on Figure 9. From this point on the data analysis is exactly the same as that used on the LV data.

An accurate geometrical representation of the adhesive patch is crucial to the performance of this method. The thickness profile of the adhesive patch across the test plate shown in Figure 9 was measured with a profilometer with approximately 4 micron steps. Figure 10 shows the result of this measurement. The adhesive layer was 
approximately $0.836 \mathrm{~mm}$ thick at the edges and $0.65 \mathrm{~mm}$ thick in the centre. These 3 critical measurement points were used to create a spline curve in COMSOL to approximate the adhesive geometry.

Rayleigh damping has been proven to be effective at modelling attenuation in Lamb waves [30] and was used to model damping in the adhesive. For the adhesive material, the $\alpha$ damping value was set to 0 and an arbitrary value of 3e-9 was assigned to $\beta$, which is similar to that used by Gresil and Giurgiutiu [31]. The exact coefficient value is not critical since only frequency and not amplitude characteristics were compared between the computational and experimental results. Unlike amplitude which is driven by the damping value, the frequency is dominated by the thickness and modulus of the adhesive.

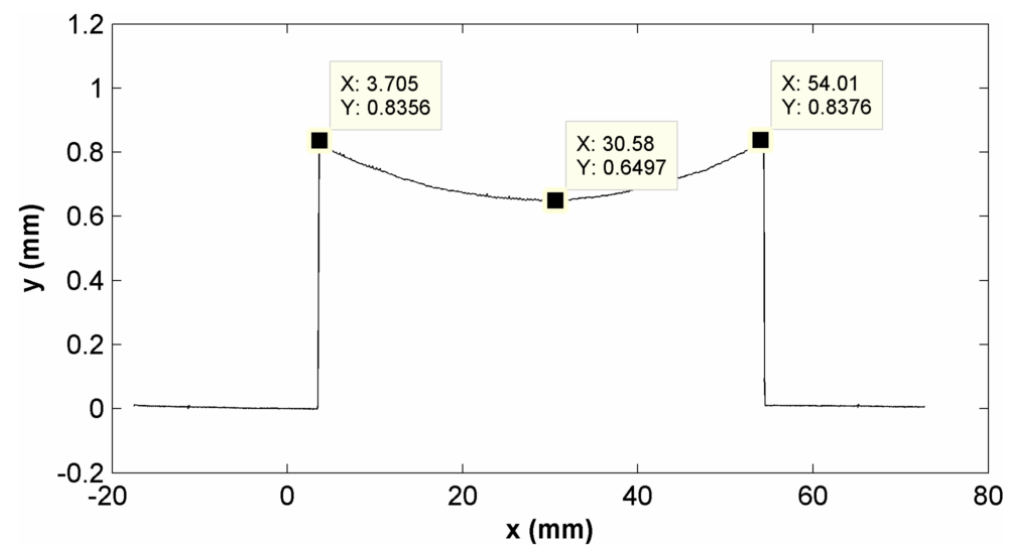

Figure 10 Profile across the adhesive. $\mathrm{X}$ axis is in the same direction as upstream/downstream scan lines. $\mathrm{Y}$ axis is in the out of plane direction to measure thickness. Note: aspect ratio is not 1:1.

A Particle Swarm Optimisation (PSO) [32] technique was used to optimise the material properties of the adhesive. The PSO used here is similar to that reported by Ong et al [22] which was used to determine material properties in a woven composite. The optimisation method is presented in a simplified form in Figure 11. The finite element model was interfaced with the PSO algorithm programmed in MATLAB 2012a where the material properties, namely the Poisson's ratio and Young's modulus of the adhesive, were optimised. This process involved the iterative modification of the properties until the finite element model predicted an attenuation spectrum which fit that measured by LV. 


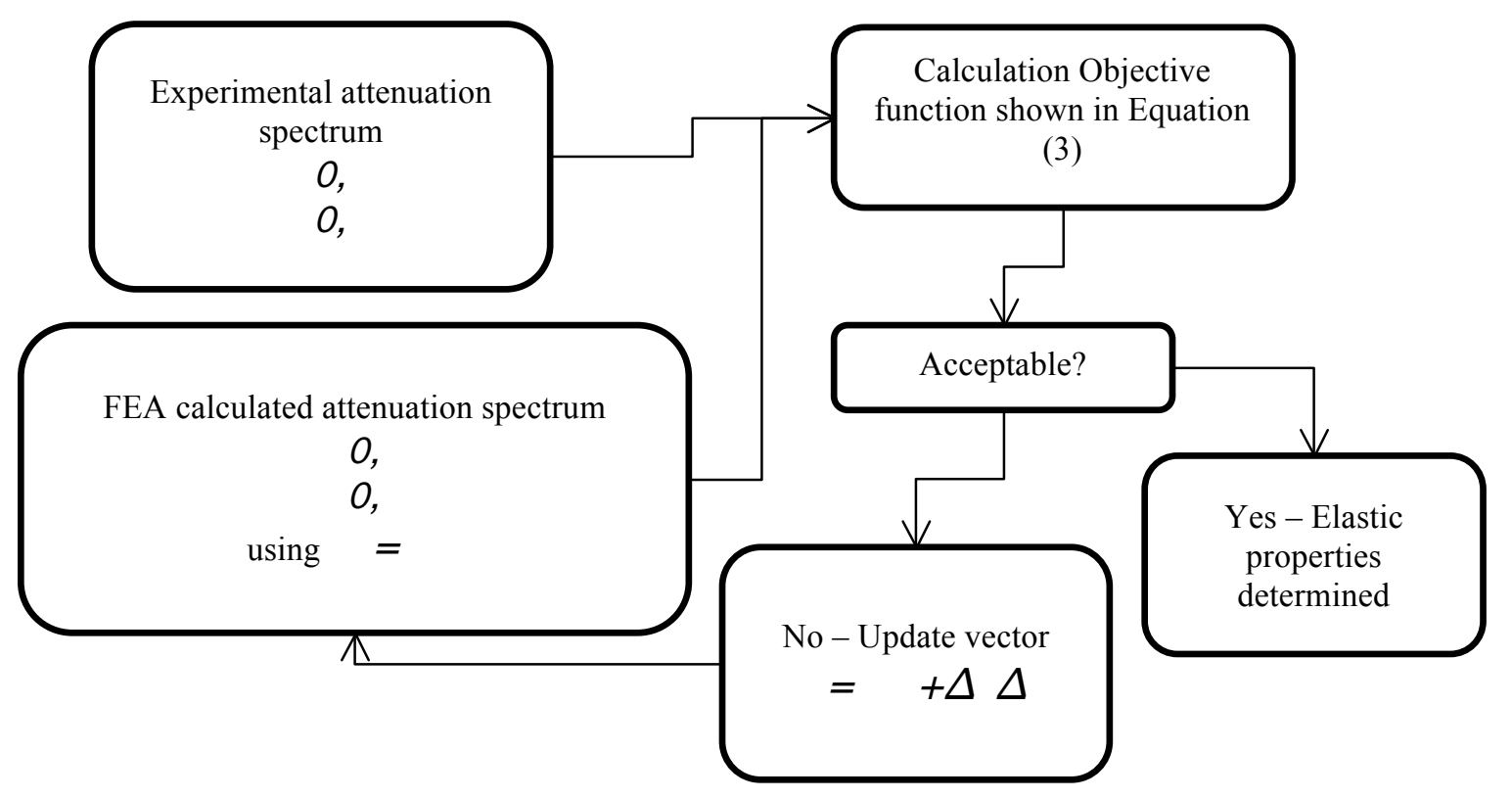

Figure 11 Flow chart describing the particle swarm optimisation algorithm.

The optimisation is implemented as follows. The two material properties used to define the adhesive are treated as a position vector $(x)$ in a 2 dimensional space;

$$
x=E v
$$

Equation 4

The process is guided by the objective function which compares the finite element model prediction of the dispersion characteristics at position vector $(x)$ against LV derived dispersion characteristics. The objective function used in this case is the minimisation of the function described by Equation 5 which measures the average gap between the experimental and simulated attenuation spectrums with both $\mathrm{A}_{0}$ and $\mathrm{S}_{0}$ given equal weighting.

$$
O E, v=1 n n A f n A O, \exp -A f n A O, \operatorname{sim}+1 n n A f n S O, \exp -A f n S O, \operatorname{sim}
$$

Equation 5

Where $A\left(f_{n}\right)$, is the attenuation value at frequency $f_{n}$.

The Poisson's ratio and Young's modulus obtained from the optimisation process are shown in Table 4. There is good agreement between this Young's modulus and that determined using the two previously described ultrasonic methods.Error! Reference source not found. Figure 12 show the resulting attenuation spectrum from the model after optimisation. Figure 12 shows a sizable amplitude gap in the $800-900 \mathrm{kHz}$ region which 
stems from using an arbitrary Rayleigh damping value rather than a measured one. However, the damping amplitude is not important because the frequency location of the attenuation minima is the physical aspect used to determine Young's modulus. In the case of Figure 12 there is only $50 \mathrm{kHz}$ error in the minima locations.

Table 4 Attenuation spectrum method results.

\begin{tabular}{|c|c|}
\hline Young's modulus $(\mathrm{GPa})$ & 3.78 \\
\hline Poisson's ratio & 0.41 \\
\hline
\end{tabular}

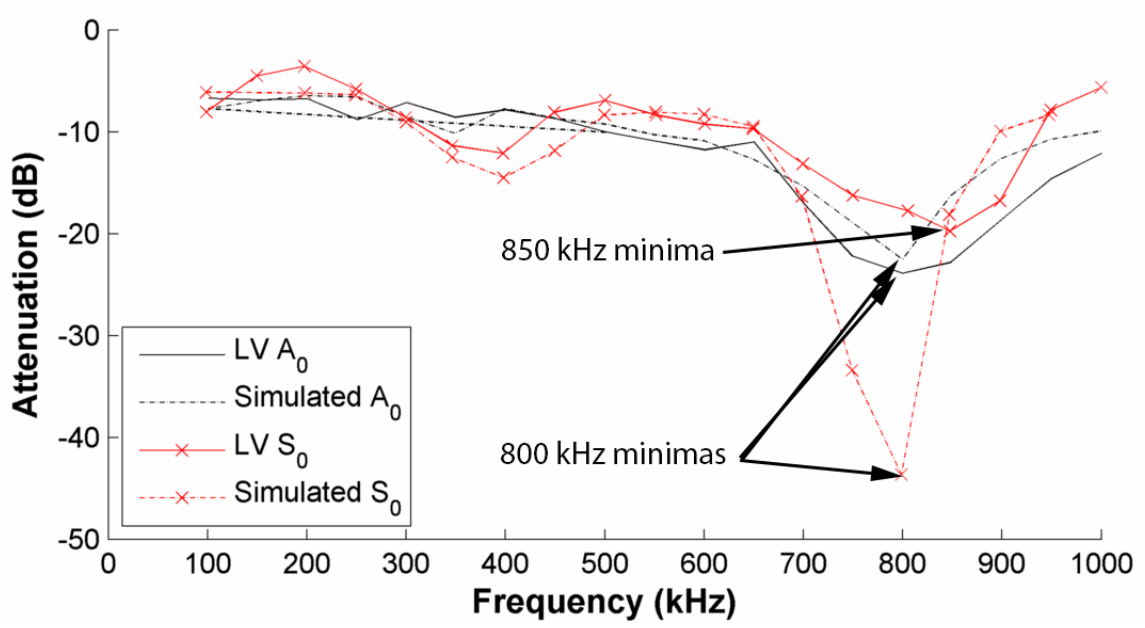

Figure $12 \quad A_{0} \& S_{0}$ attenuation spectrums after optimisation. (LV=Laser vibrometry)

\subsection{Summary of Results}

Table 6 summarises the material properties of FM300-2K measured from the four techniques described previously. The results show a good agreement in the elastic modulus obtained from the ultrasonic methods. This corroborates the findings published by Burst and Adams [23] where it was stated that properties obtained from bulk specimens are interchangeable with thin film properties. It is also evident that there is a substantial difference between these values and the published modulus. An approximate modulus increase of $1 \mathrm{GPa}(60 \%)$ was observed using ultrasonic testing methods when compared to published values based on quasi-static testing. Since Lamb waves result in high strain rates, a higher elastic modulus is expected [14]. Within the three ultrasonic methods, attenuation spectrum and bulk wave ultrasonics are almost identical while dispersion curve fitting results in a Young's modulus approximately $0.12 \mathrm{GPa}$ higher. This is likely due to the inherent error when manual optimisation was used in dispersion curve fitting since the quality of fit was subjective.

Table 6 Summary of FM300-2K material properties. Note: * Cytec only provide shear modulus, Young's modulus 


\begin{tabular}{|l|c|c|c|c|c|c|}
\hline Source & Cytec & Tong et al & $\begin{array}{c}\text { Quasi- } \\
\text { static } \\
\text { testing }\end{array}$ & $\begin{array}{c}\text { Dispersion } \\
\text { curve fitting }\end{array}$ & $\begin{array}{c}\text { Attenuation } \\
\text { spectrum }\end{array}$ & $\begin{array}{c}\text { Bulk wave } \\
\text { ultrasonics }\end{array}$ \\
\hline Young's modulus (GPa) & $2.432^{*}$ & 2.923 & 2.9 & 3.9 & 3.78 & 3.74 \\
\hline Poisson's ratio & $\mathrm{n} / \mathrm{a}$ & 0.34 & $\mathrm{n} / \mathrm{a}$ & $\mathrm{n} / \mathrm{a}$ & 0.41 & 0.37 \\
\hline
\end{tabular}

\section{Case study: Lap joint specimen}

A case study was conducted to demonstrate the inaccuracies that can occur when statically obtained material properties are applied to Lamb wave simulation. In this investigation, a $1.6 \mathrm{~mm}$ aluminium plate was used featuring an aluminium doubler bonded with FM300-2K as shown in Figure 13. The specimen was fabricated and the "area of interest", labelled in Figure 13, was scanned using LV. The "area of interest" was chosen to examine the behaviour of Lamb waves as they propagate into the doubler. Lamb waves were excited using a $\varnothing 10 \mathrm{~mm}$ x $1 \mathrm{~mm}$ thick Ferroperm piezoceramic disc of type Pz27 driven by a 5 cycle Hanning windowed sinusoid with a centre frequency of $300 \mathrm{kHz}$.

Two numerical studies were performed to calculate the mode conversion of an incident fundamental symmetric $\left(\mathrm{S}_{0}\right)$ into the fundamental anti-symmetric $\left(\mathrm{A}_{0}\right)$ Lamb wave mode when it transited from the adherend to the bonded region. These calculations were performed using properties provided by the supplier of the film adhesive (i.e. based on static tests) in one model and those determined using the attenuation spectrum method in the other. The two numerical models had to be reduced down to the "area of interest" due to computational limitations. This resulted in the model shown in Figure 14. In an attempt to minimise edge reflections from the cut down model, a damped boundary was added. The model was created in UGS FEMAP and solved with Nastran's transient dynamic solver. The time step was set to $0.04 \mu \mathrm{s}$ and the mesh size to $0.6 \mathrm{~mm}$, ensuring ample temporal and spatial resolution. The results were compared with experimental results. 


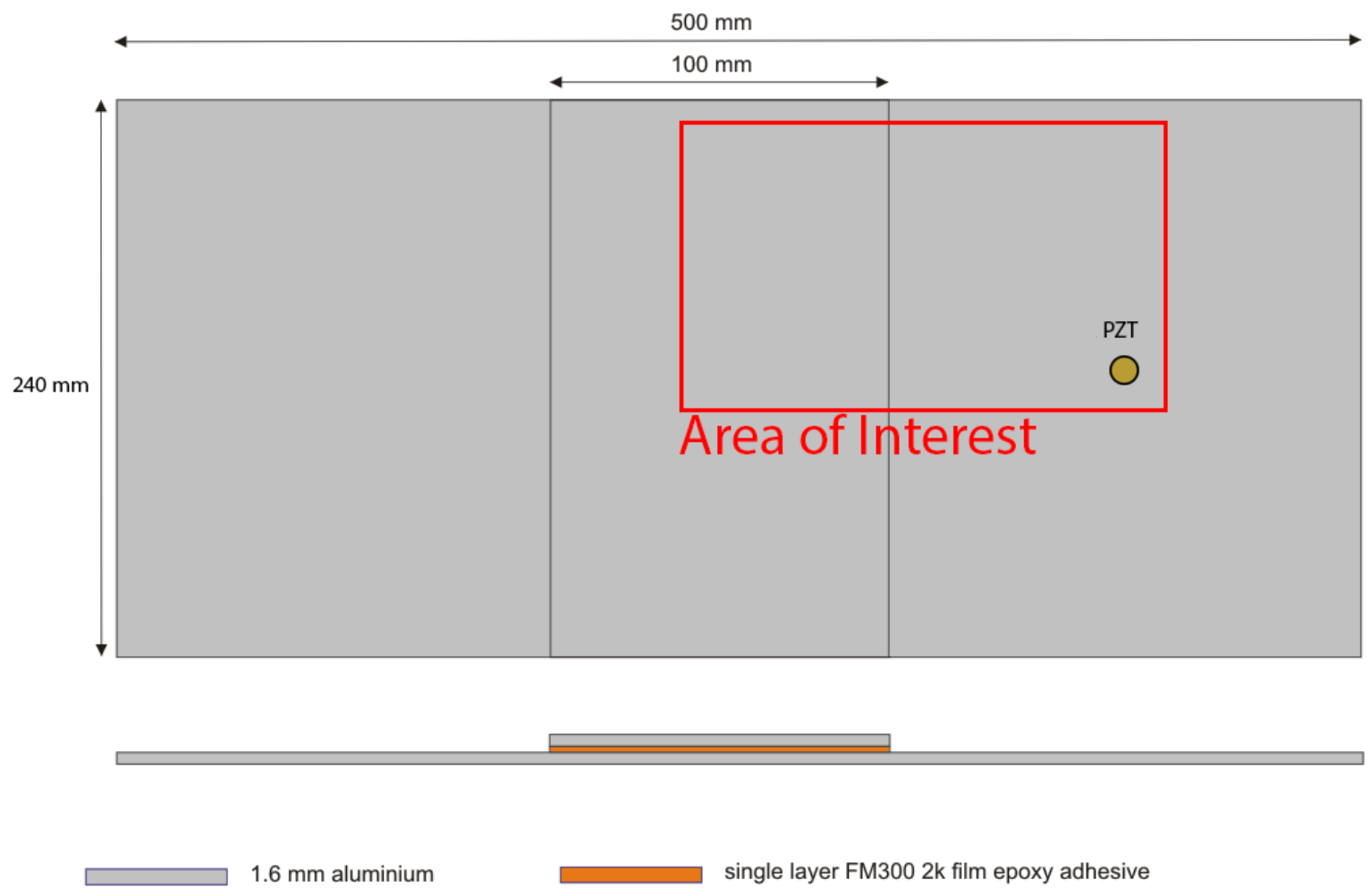

Figure 13 Lap joint specimen used in experimental laser vibrometry.

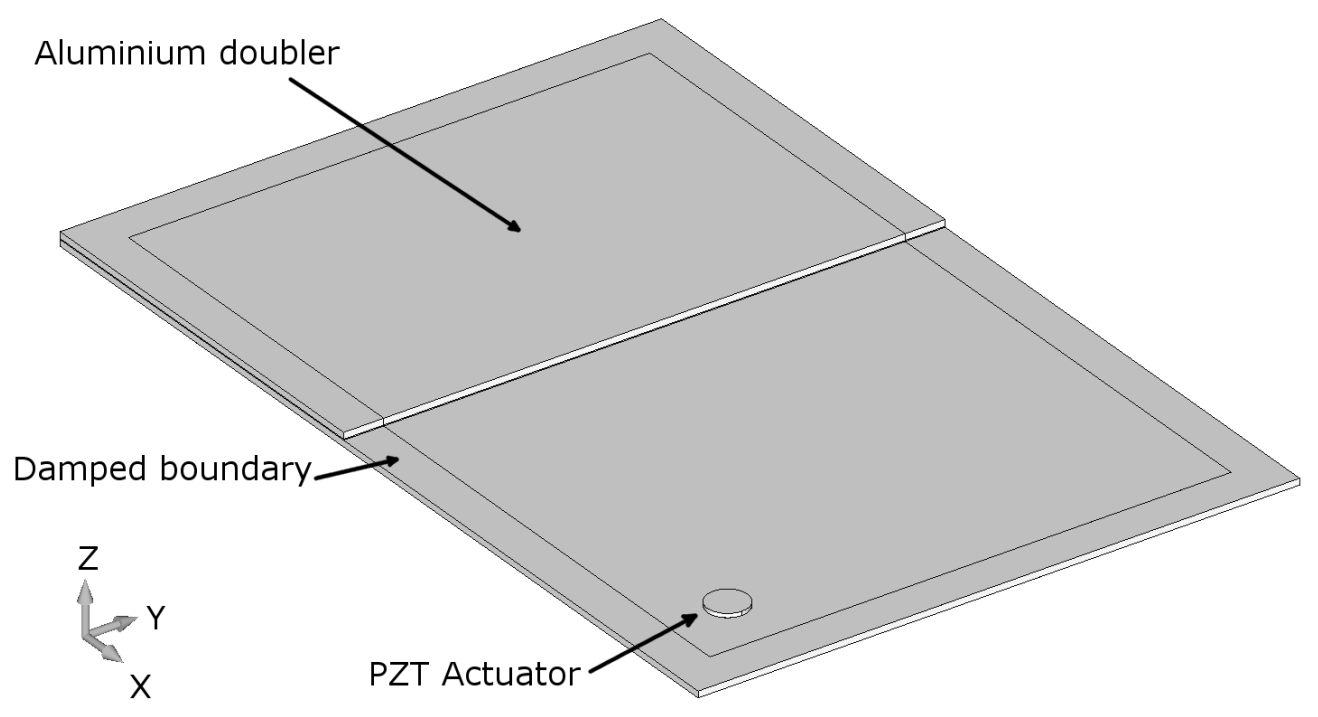

Figure 14 Reduced lap joint specimen used in the numerical model.

The displacement fields $40 \mu$ s after excitation are shown in Figure 15. On initial observation, there does not appear to be significant differences between the numerical and experimental results. Both models (Figure $15 \mathrm{a} \& \mathrm{~b})$ correctly predict the shape of the wave fronts and the wavelengths appear to be the same as those measured experimentally (Figure 15c). This is because the measured adhesive thickness was only $0.23 \mathrm{~mm}$ thick 
which is $6 \%$ of the total thickness in the doubler region. Figure $15 \mathrm{a}$ has additional labels which identify features of interest. The study focussed on the $\mathrm{S}_{0}$ mode and mode converted $\mathrm{A}_{0}\left(\mathrm{MC}-\mathrm{A}_{0}\right)$ mode which originated from an incident $\mathrm{S}_{0}$ mode propagating through the bonded region. The MC- $\mathrm{A}_{0}$ mode, labelled in Figure 15a, appeared in the doubler region well before the incident $\mathrm{A}_{0}$ mode had arrived, which confirmed it was produced by modeconversion.

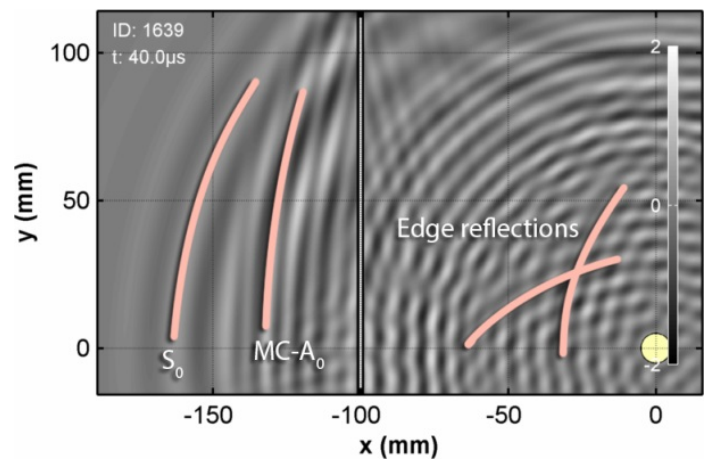

a) Acousto-ultrasonic derived

properties

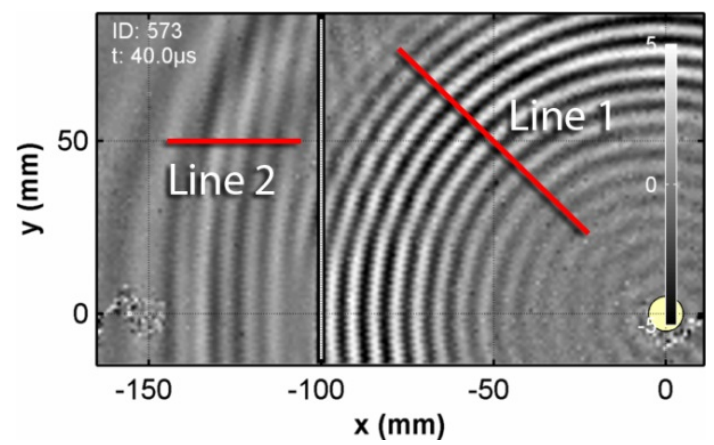

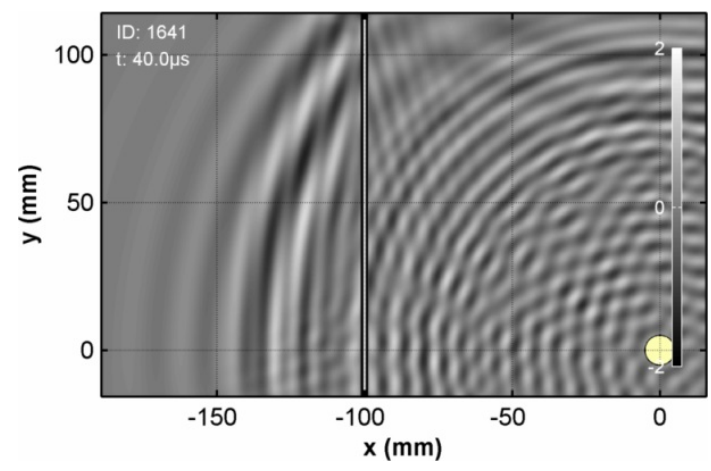

b) Statically derived properties

\section{c) Experimental}

Figure 15 Displacement field at $40 \mu s$.

Further inspection was done by $2 \mathrm{D}$ FFT analysis to ascertain the individual amplitude of $\mathrm{S}_{0}$ and $\mathrm{A}_{0}$ modes before and after entering the doubler. A 2D FFT was applied to data acquired along Line 1, which is shown in Figure $15 \mathrm{c}$, to determine the amplitude of the incident $\mathrm{S}_{0}$ mode. The time window for this $2 \mathrm{D}$ FFT was $10-20 \mu \mathrm{s}$ which favoured the fast moving $\mathrm{S}_{0}$ mode. Figure 16 shows the modal content from this $2 \mathrm{D}$ FFT overlaid on the analytical dispersion curve for a $1.6 \mathrm{~mm}$ thick aluminium plate. The results from this point onward were normalised with their respective $S_{0}$ mode magnitudes as shown in Equation 6. This assisted with the direct 
comparisons between experimental and numerical data. Figure $16 \mathrm{a} \& \mathrm{~b}$ are identical because the wave had not yet reached the doubler where the material properties of the adhesive in the models differ.

\section{NormalisedWave Field $\mathbf{i}=$ Wave Fieldi Soincident $i$}

Where $i=$ experimental resultsmodel with
acousto-ultrasonic derived propertiesmodel with

Equation 6

statically derived properties

Figure 17 shows the 2D FFTs along line 2 (shown in Figure 15c) overlaid with predicted dispersion curves for aluminium/FM300-2K/aluminium plate within a time window of 15-40 $\mu \mathrm{s}$. The time window was chosen to incorporate the $\mathrm{MC}-\mathrm{A}_{0}$ and $\mathrm{S}_{0}$ modes propagating through the doubler prior to the arrival of the incident $\mathrm{A}_{0}$ mode. Figure 17 highlights the key consequence from using incorrect adhesive properties. When published properties were used, the resulting proportions of $M C-\mathrm{A}_{0}$ and $\mathrm{S}_{0}$ modes (Figure 17b) did not match the experimental result (Figure 17c). Figure $17 \mathrm{~b}$ shows a much stronger $\mathrm{S}_{0}$ mode which stemmed from the lower adhesive modulus which allowed more in-plane motion resulting in a larger $\mathrm{S}_{0}$ mode amplitude. When optimised properties were used to model the adhesive, an excellent agreement between the experimental and computational results was obtained (see Figure $17 \mathrm{a} \& \mathrm{c}$ ). For a quantitative comparison, the peak amplitude values from the 2D FFTs presented in Figure 16 and Figure 17 are tabulated in Table 7 . While the MC-A $\mathrm{A}_{0}$ mode was predicted well with either property set, an error of $32 \%$ was recorded for the transmitted $\mathrm{S}_{0}$ mode in the doubler section when published properties were used. This demonstrates the relative improvement in simulation accuracy when using ultrasonic derived material properties to model Lamb waves over quasi-statically derived properties. 


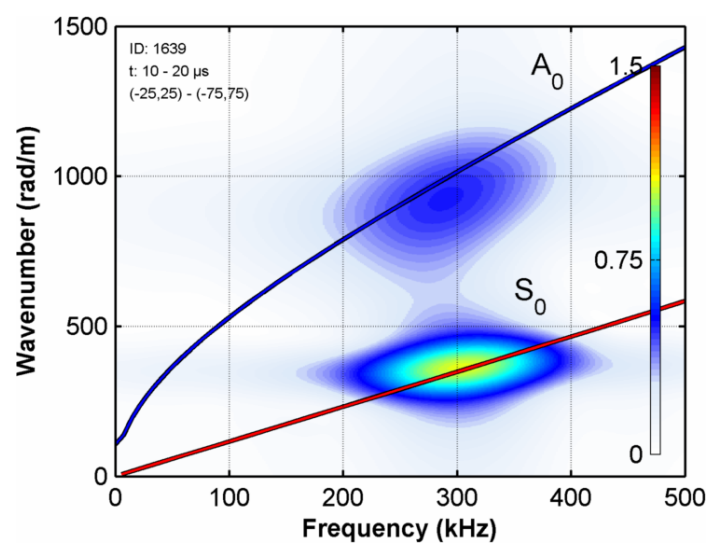

a) UItrasonically derived properties

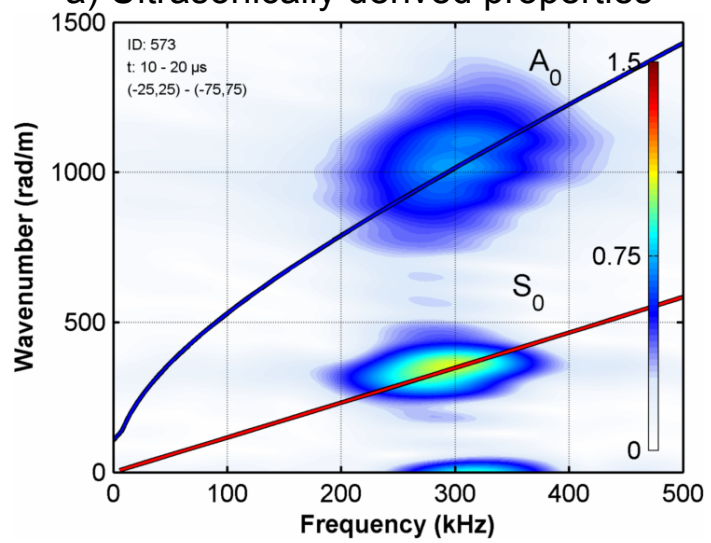

c) Experimental

Figure 16 2D FFT showing the incident $A_{0}$ and $S_{0}$ amplitudes (along line 1).

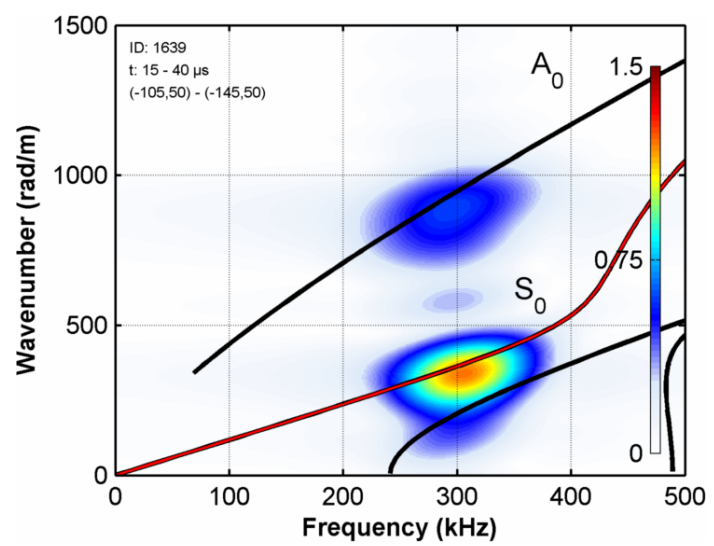

a) Ultrasonically derived properties

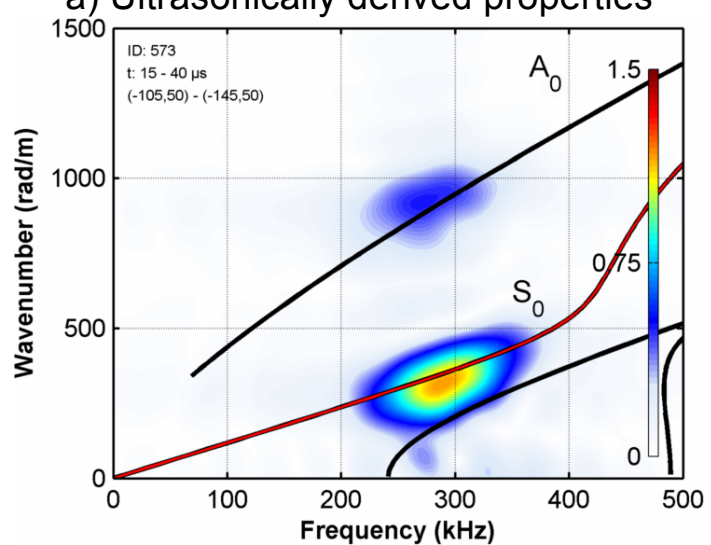

c) Experimental

Figure 17 2D FFT showing $A_{0}$ and $S_{0}$ amplitudes on the doubler (along line 2).

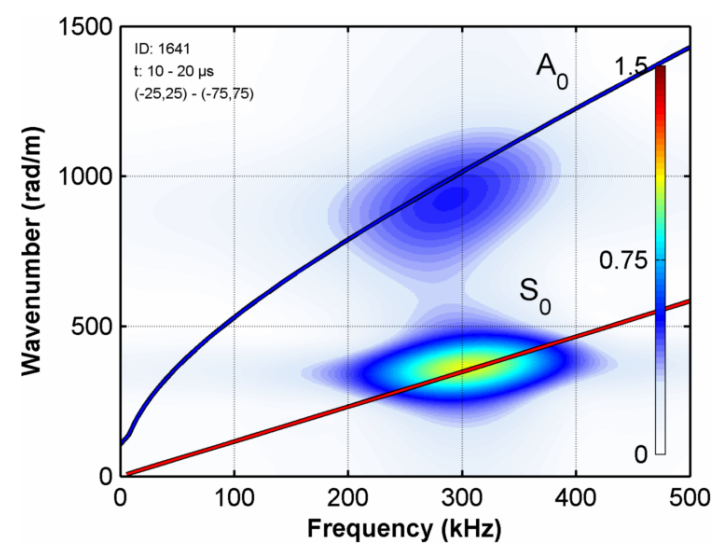

b) Statically derived properties

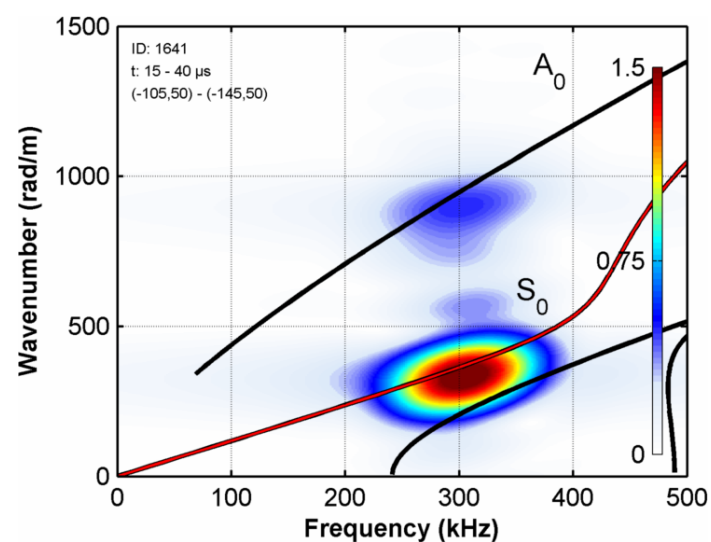

b) Statically derived properties 
Table 7 Amplitude measurements from 2D FFT along line 2.

\begin{tabular}{l|c|c|}
\multirow{2}{*}{} & \multicolumn{2}{|c|}{ Line 2 } \\
\cline { 2 - 3 } & ${\text { MC- } \mathrm{A}_{0}}^{*}$ & $\mathrm{~S}_{0}$ \\
\hline \multirow{2}{*}{ Experimental } & 0.51 & 1.15 \\
\hline $\begin{array}{l}\text { FE (Ultrasonically derived } \\
\text { properties) }\end{array}$ & 0.58 & 1.16 \\
\hline FE (Published properties) & 0.47 & 1.53
\end{tabular}

\section{Conclusion}

The results presented in this paper showed that material properties originating from quasi-static testing would result in poor modelling of Lamb wave propagation. These properties resulted in wavenumbers which were over predicted by approximately $20 \%$ as shown in Figure 6 . In order to improve modelling accuracy, three ultrasonic test methodologies were applied to obtain the elastic properties of FM300-2K epoxy film adhesive. All three methods returned similar material properties which could accurately model Lamb waves and predict the correct wavenumber for each mode. The three ultrasonic methods recorded a Young's modulus approximately $60 \%$ higher which is in line with a study by Gilat et al [14] where higher strain rates result in higher modulus. This difference is thought to stem from the viscoelastic behaviour of the adhesive which makes it sensitive to the different strain rates associated with structural/static loading and ultrasonic wave propagation.

In order to demonstrate the impact on accurate Lamb wave modelling, a case study was presented where propagating Lamb waves were modelled in a lap joint specimen alongside an experimental study for reference data. The study showed that relying on quasi-statically determined properties can lead to significant simulation errors. When static properties were used, the amplitude of $\mathrm{S}_{0}$ in the doubler was shown to have a $32 \%$ error. Conversely, the ultrasonically determined properties resulted in a numerical model which closely resembled the experiment.

Finally, a note has to be made concerning the three ultrasonics approaches employed in this paper. The dispersion curve fitting method was simple to implement but fabricating a monolithic plate from thin film adhesive stock posed experimental challenges. Similarly, although bulk wave testing is well established, the thick slab required is also challenging to fabricate given it is an unconventional use of structural film adhesive. The specimen required for the attenuation spectrum method was the easiest to fabricate and best represents 
normal use of the film adhesive. Consequently the attenuation spectrum method is the method advocated in this

paper.

\section{Acknowledgements}

The authors gratefully acknowledge the Office of Naval Research for the support of this work under the Naval International Cooperative Opportunities in Science and Technology Program (Grant No. N62909-12-1-7005).

\section{References}

1. Staszewski, W.J., B.C. Lee, and R. Traynor, Fatigue crack detection in metallic structures with Lamb waves and 3D laser vibrometry. Measurement Science \& Technology, 2007. 18(3): p. 727-739.

2. Ong W H, C.W.K., Redirection of Lamb Waves for Structural Health Monitoring. Smart Materials Research, 2012. 2012(Article ID 718686).

3. Ong, W.H. and W.K. Chiu, Enhancement of Lamb wave-based in situ structural health monitoring through guided local geometry changes. Structural Health Monitoring, 2013. 12(4): p. 339-358.

4. Packo, P., T. Bielak, A.B. Spencer, W.J. Staszewski, T. Uhl, and K. Worden, Lamb wave propagation modelling and simulation using parallel processing architecture and graphical cards. Smart Materials and Structures, 2012. 21(7).

5. Staszewski, W.J. and B.C. Lee, Modelling of Lamb waves for damage detection in metallic structures: Part I. Wave propagation. Smart Materials \& Structures, 2003. 12(5): p. 804-814.

6. Ostachowicz, W., P. Kudela, and M. Radzienski, Experimental Validation of Algorithms for Wave Propagation Modeling in 2D and 3D Structures Based on the Spectral Element Method. Structural Health Monitoring 2011: Condition-Based Maintenance and Intelligent Structures, Vol 1 and Vol 2, 2011: p. 915-922.

7. Lee, B.C. and J. Staszewski, Numerical modelling and simulations for optimal sensor location in damage detection with Lamb waves. Modeling, Signal Processing, and Control for Smart Structures 2007, 2007. 6523.

8. Ong, W.H. and W.K. Chiu, Numerical modelling of scattered Lamb waves through varied damage size in challenging geometry. Structural Health Monitoring, 2013. 12(3): p. 278-295. 
9. Ostachowicz, W. and P. Kudela, Wave Propagation Numerical Models in Damage Detection Based on the Time Domain Spectral Element Method. 9th World Congress on Computational Mechanics and 4th Asian Pacific Congress on Computational Mechanics, 2010. 10.

10. Staszewski, W.J. and B.C. Lee, Modelling of Lamb waves for damage detection in metallic structures: Part II. Wave interactions with damage. Smart Materials \& Structures, 2003. 12(5): p. 815-824.

11. Ong, W.H., W.K. Chiu, N. Rajic, and C. Rosalie, The inadequacy of elastic properties from tensile tests for Lamb wave analysis, in The 6th Internatioal Conference on Computational Methods (ICCM2015)2015: Auckland, New Zealand.

12. Ambrozinski, L., P. Packo, L. Pieczonka, T. Stepinski, T. Uhl, and W.J. Staszewski, Identification of material properties - efficient modelling approach based on guided wave propagation and spatial multiple signal classification. Structural Control \& Health Monitoring, 2015. 22(7): p. 969-983.

13. Rochefort, M.A. and H.F. Brinson, Nonlinear viscoelastic characterization of structural adhesives, 1983, NASA. NASA Contractor Report 172279

14. Gilat, A., R.K. Goldberg, and G.D. Roberts, Strain rate sensitivity of epoxy resin in tensile and shear loading. Journal of Aerospace Engineering, 2007. 20(2): p. 75-89.

15. Chiu, W.K. and R. Jones, Unified Constitutive Model for Thermoset Adhesive, Fm73. International Journal of Adhesion and Adhesives, 1995. 15(3): p. 131-136.

16. Zhou, Y. and P.K. Mallick, Effects of temperature and strain rate on the tensile behavior of unfilled and talc-filled polypropylene. Part I: Experiments. Polymer Engineering and Science, 2002. Vol. 42(No. 12): p. 2449-2460.

17. Guillemenet, J., S. Bistac, and J. Schultz, Relationship between polymer viscoelastic properties and adhesive behaviour. International Journal of Adhesion and Adhesives, 2002. 22(1): p. 1-5.

18. Maheri, M.R. and R.D. Adams, Determination of dynamic shear modulus of structural adhesives in thick adherend shear test specimens. International Journal of Adhesion and Adhesives, 2002. 22(2): p. 119-127.

19. Lowe, M.J.S., R.E. Challis, and C.W. Chan, The transmission of Lamb waves across adhesively bonded lap joints. Journal of the Acoustical Society of America, 2000. 107(3): p. 1333-1345.

20. Francesco, L.d.S. and R. Piervincenzo, Propagation of ultrasonic guided waves in lap-shear adhesive joints: Case of incident a0 Lamb wave. The Journal of the Acoustical Society of America, 2004. 115. 
21. Spencer, A.B., K. Worden, W.J. Staszewski, J.A. Rongong, and N.D. Sims, An optimisation scheme based on the local interaction simulation approach and Lamb waves for elastic property estimation in multi-layered composites. Shock and Vibration, 2012. 19(5): p. 1027-1040.

22. Ong, W.H., N. Rajic, W.K. Chiu, and C. Rosalie, Determination of the elastic properties of woven composite panels for Lamb wave studies. Composite Structures, 2016. 141: p. 24-31.

23. Burst, N. and D.O. Adams, Investigating the Thin-Film Versus Bulk Material Properties of Structural Adhesives 2008, Office of Aviation Research and Development: Washington, DC. DOT/FAA/AR-06/45

24. Cytec, FM 300-2 Film Adhesive Technical Data Sheet, 2011, Cytec Engineered Materials.

25. Tong, L., A. Sheppard, and D. Kelly, Relationship between Surface Displacement and Adhesive Peel Stress in Bonded Double Lap Joints. International Journal of Adhesion and Adhesives, 1995. 15(1): p. 43-48.

26. Olympus, Panametrics Ultrasonic Transducers: Wedges, Cables, Test Blocks, 2013, Olympus.

27. Alleyne, D.N. and P. Cawley, A 2-Dimensional Fourier-Transform Method for the Quantitative Measurement of Lamb Modes. leee 1990 Ultrasonics Symposium : Proceedings, Vols 1-3, 1990: p. 1143-1146.

28. Lowe, M., DISPERSE, 1996-2007, Imperial College, Department of Mechanical Engineering: London.

29. Ong W H, R.C., Rajic N, Chiu W K. Determination of elastic properties in a plate by Lamb wave analysis and particle swarm optimisation. in 7th International conference on materials for advanced technologies. 2013. Suntec Singapore

30. Ramadas, C., K. Balasubramaniam, A. Hood, M. Joshi, and C.V. Krishnamurthy, Modelling of attenuation of Lamb waves using Rayleigh damping: Numerical and experimental studies. Composite Structures, 2011. 93(8): p. 2020-2025.

31. Gresil, M. and V. Giurgiutiu, Prediction of attenuated guided wave propagation in carbon fiber composites, in The 19th international conference on composite materials2013: Montreal, Canada.

32. Shi, Y.H. and R. Eberhart, A modified particle swarm optimizer. 1998 leee International Conference on Evolutionary Computation - Proceedings, 1998: p. 6973. 
